Bangladesh J. Zool. 42(1): 105-116, 2014

\title{
SPECIES DIVERSITY AND HABITAT PREFERENCES OF AMPHIBIAN FAUNA IN SIX PROTECTED AREAS OF BANGLADESH
}

\author{
Md. Kamrul Hasan and Mohammed Mostafa Feeroz \\ Department of Zoology, Jahangirnagar University, Savar, Dhaka, Bangladesh
}

\begin{abstract}
Study on amphibian species diversity and habitat preferences was conducted in six protected areas of Bangladesh between March 2011 and July 2012. A total of 32 species of amphibians were recorded under six families. Family Dicroglossidae comprised the highest number of species (12) where Bufonidae the lowest ( 1 species). Among these species 34\% were uncommon, 31\% common, 19\% rare and $16 \%$ very common. Alpha diversity was the highest in DudpukuriaDhopachari Wildlife Sanctuary (28) and the lowest in Sitakunda Eco-park (13). Beta diversity was the highest (11) between Inani Protected Forest and Sitakunda Eco-park and the lowest (3) between Dudpukuria-Dhopachari Wildlife Sanctuary and Teknaf Wildlife Sanctuary. Jaccard index of similarity among the amphibian communities was the highest $(\mathrm{J}=0.90)$ between Dudpukuria-Dhopachari Wildlife Sanctuary and Teknaf Wildlife Sanctuary and the lowest $(J=0.54)$ between Inani Protected Forest and Sitakunda Eco-park. Fifty percent of the species were found to use more than two habitats, while only $16 \%$ species were restricted to a single habitat. Significant number of the species (20 species) were found to use forest edges, aquatic environment (19 species), forest floor (15 species), agricultural land (13 species), bushes (7 species) and tree habitats ( 3 species).
\end{abstract}

Key words: Amphibia, habitat, diversity, protected areas, Bangladesh.

\section{INTRODUCTION}

Amphibians are cold blooded vertebrates and aquatic environment is must in a part of their life cycle. Except the caecilians, amphibians have paired limbs and naked skin. The caecilians have scales that hidden under skin. Frogs are both diurnal and nocturnal but toads are almost nocturnal. They are the earliest tetrapod land vertebrates. There are 7,044 species of amphibians in three orders exist today in the world (Frost, 2013). Amphibians occupy a great variety of climatic and ecological zones (Hall and Henry, 1992).

The geographic position of Bangladesh is at the junction of the IndoHimalaya and Indo-Chinese sub-regions (Stanford, 1991). Bangladesh belongs to two of the 20 Global Ecological Zones (FAO, 2001). Depending on the variations in temperature, rainfall, soil quality, hydrological conditions and floral-faunal distribution, 25 bio-ecological zones have been recognized throughout Bangladesh (Nishat et al. 2002). Bangladesh has three major forest types, viz., mixed evergreen, moist deciduous and mangrove (Feeroz et al. 2012) which include 2.21 million hectares of land (NFA, 2007). Freshwater swamps are distributed in the northeast basin of the country. About $50 \%$ of the land surface of the country including rivers, haors, lakes, baors (oxbow lakes), beels 
(floodplain depressions) and ponds are considered as wetlands (Feeroz et al. 2012). These diverse habitat types of the country support a significant number of wild animals as well as amphibians.

Protected Areas (PAs) of Bangladesh covers about 10.7\% of the forest areas of the country. A total of 34 PAs have been declared in the form of National Parks and Wildlife Sanctuaries (Feeroz, 2013). Apart from these 34 PAs, two botanical gardens, two safari parks and five eco-parks have also been established to ensure the protection and conservation of wild animals as well as the amphibians of the country (Feeroz et al. 2012).

Amphibians play an important role in biological pest control. All adult amphibians are carnivorous and the main predator of many harmful insects and other pests. The larvae of frogs and toads feed mainly on algae and bits of dead animals in water, diatoms, planktons or other small organisms. Thus, they play an important role in the ecosystem.

In Bangladesh researches on amphibians are still in infancy. The exact number of amphibian species in Bangladesh is still a matter of debate. However, a total of 22 (IUCN, 2000), 26 (Khan, 2004), 34 (Kabir et al., 2009) and 42 (Khan, 2010) amphibian species have been reported from Bangladesh though none of the list was purely based on voucher specimen, photographic documents or any other confirm evidences. Site specific information on amphibian diversity and their habitat preference is also very few. Keeping this in mind the present study was conducted on amphibian diversity and their habitat preferences in six protected areas of Bangladesh.

\section{MATERIAL AND METHODS}

Study area: The study was conducted between March 2011 and July 2012 as a part of the biodiversity monitoring in selected forests of Bangladesh. Six protected areas of Bangladesh viz., Rema-Kalenga Wildlife Sanctuary (RKWS), Fashiakhali Wildlife Sanctuary (FWS), Dudpukuria-DhopacharI Wildlife Sanctuary (DDWS), Teknaf Wildlife Sanctuary (TWS), Inani Protected Forest (IPF) and Sitakunda Eco-park (SKEP) were studied. Three to five days were spent per month in each study area for the search of amphibians. All the six PAs are semi- or mixed-evergreen forests, RKWS is located in the northeastern and the rest are in the southeastern regions of the country. All these protected areas facing different level of threats because of anthropogenic activities, however, still support major herpetofauna of the country (Feeroz et al. 2011, 2012; Feeroz 2013). 
Survey:Surveys were conducted during day and night using different survey methods. Amphibian species encountered in different habitats along with the number of individuals were recorded in predesigned data sheet.

Amphibian specimens were identified with the aid of the following literature; Bossuyt and Dubois (2001), Dubois (1975), Dutta and Manamendra-Arachchi (1996), Ahmed et al. (2009), Das (2008), Kabir et al. (2009) and Smith (1935, 1943). Nomenclature for Amphibians was followed from Frost (2013). Bengali names used here from Khan (2010; and in case of unavailable names, we proposed the names).

Visual encounter survey: survey was conducted in different habitats of six protected forests in different time periods of the day and night. Individuals were detected by loud call of male during breeding season.

Pitfall traps: same number of Pitfall traps were established in different habitats of each protected forest. Each trap-line comprised three large buckets embedded in the ground, spaced $3 \mathrm{~m}$ apart, with a $1 \mathrm{~mm}$ gauge wire mesh drift fence $30 \mathrm{~cm}$ high and $15 \mathrm{~m}$ long, passing over the center of each bucket.

Opportunistic search: opportunistic searches generally comprised walking slowly through various habitats, such as bushy areas, along streams, agricultural areas or swamps, looking for amphibians, and disturbing logs, rocks or other ground debris to check for sheltering animals.

Sample collection: cryptic specimens were collected for further identification either by direct hand picking or by amphibian nets. Voucher specimens were preserved to the wildlife museum of the Department of Zoology, Jahangirnagar University.

Status: four categories were used to express the relative abundance, or status of different species (Khan, 2008). These are: Very Common (VC): species with 76-100 percent chance of being encountered when it is most active in its habitats; Common (C): species with 51-75 percent chance of being encountered; Uncommon (UC): species with 26-50 percent chance of being encountered and; Rare (R): species with 25 percent or less chance of being encountered.

\section{Habitat preference}

Amphibian habitats in these forests were divided into 6 major categories.

(i) Forest floors (Ff): include leaf litters, grass lands, fallen logs etc.; any amphibians inhabiting forest ground.

(ii) Agricultural land (Al): any sort of crop field in and around the forest area.

(iii) Forest edge ( $\mathrm{Fe})$ : periphery of the forest patches. 
(iv) Water body (Wb): permanent and temporary water either stagnant of running.

(v) Bushes (B): understory of the forest usually comprised of different small plants, shrubs and herbs; and

(vi) Tree (T): tree trunk, branch, tree-holes.

\section{Data analysis}

Measuring Diversity

Alpha: diversity within a particular area

Beta: changes in species diversity between different areas

Gama: total species over a large area or region; in this case total number of amphibian species in six study areas.

Community Similarity: Jaccard index (Jaccard, 1901) of similarity was used to determine community similarity between two protected areas.

$$
\begin{aligned}
J=\frac{i}{(a+b-j)} \quad \text { where, } J=\text { Jaccard index of similarity } \\
a=\text { number of species at site ' } a \text { ' } \\
b=\text { number of species at site 'b' } \\
j=\text { number of species occurring at both sites }
\end{aligned}
$$

\section{RESULTS AND DISCUSSION}

Species diversity: a total of 32 amphibian species inder 6 families were recorded from six protected areas (Table 1). Number of species in each protected area varied from 13 to 28. Dudpukuria-Dhopachari Wildlife Sanctuary (DDWS) supports the highest number of species (28) where Sitakunda Eco-park (SKEP) supports the lowest number of species (13). Family Dicroglossidae comprised $38 \%$ of the population (12 species), followed by Rhacophoridae $22 \%$ (7 species), Ranidae $19 \%$ (6 species), Microhylidae 13\% (4 species), Megophoridae 6\% (2 species) and Bufonidae 3\% (1 species). All the six protected areas had the highest number of frogs from the Family Dicroglossidae (5 to 12 species) and the lowest number from Bufonidae (1 species) (Fig. 1).

Alpha diversity was highest in DDWS (28) followed by Fashiakhali Wildlife Sanctuary (FWS) and Teknaf Wildlife Sanctuary (TWS) (27 each), Inani Protected Forest (IPF) (24), Rema-Kalenga Wildlife Sanctuary (RKWS) (23) and Stakunda Eco-part (SKEP) (13) (Table 1). Beta diversity between RKWS vs FWS was 6, FWS vs DDWS 5; DDWS vs TWS 3; TWS vs IPF 3; IPF vs SKEP11 and SKEP vs RKWS10 (Table 1). Gama diversity for all the six protected areas was 32 (Table $1)$. 


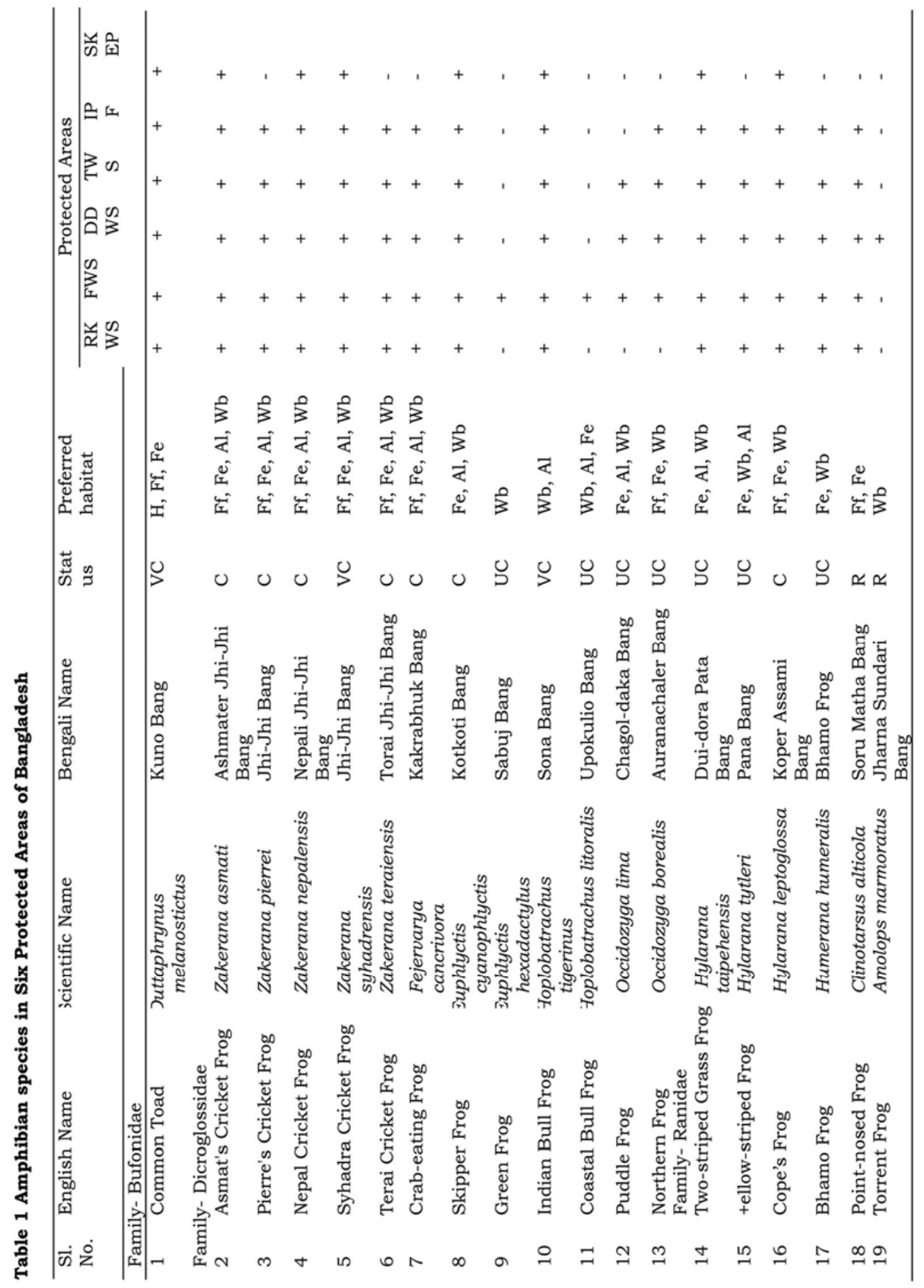




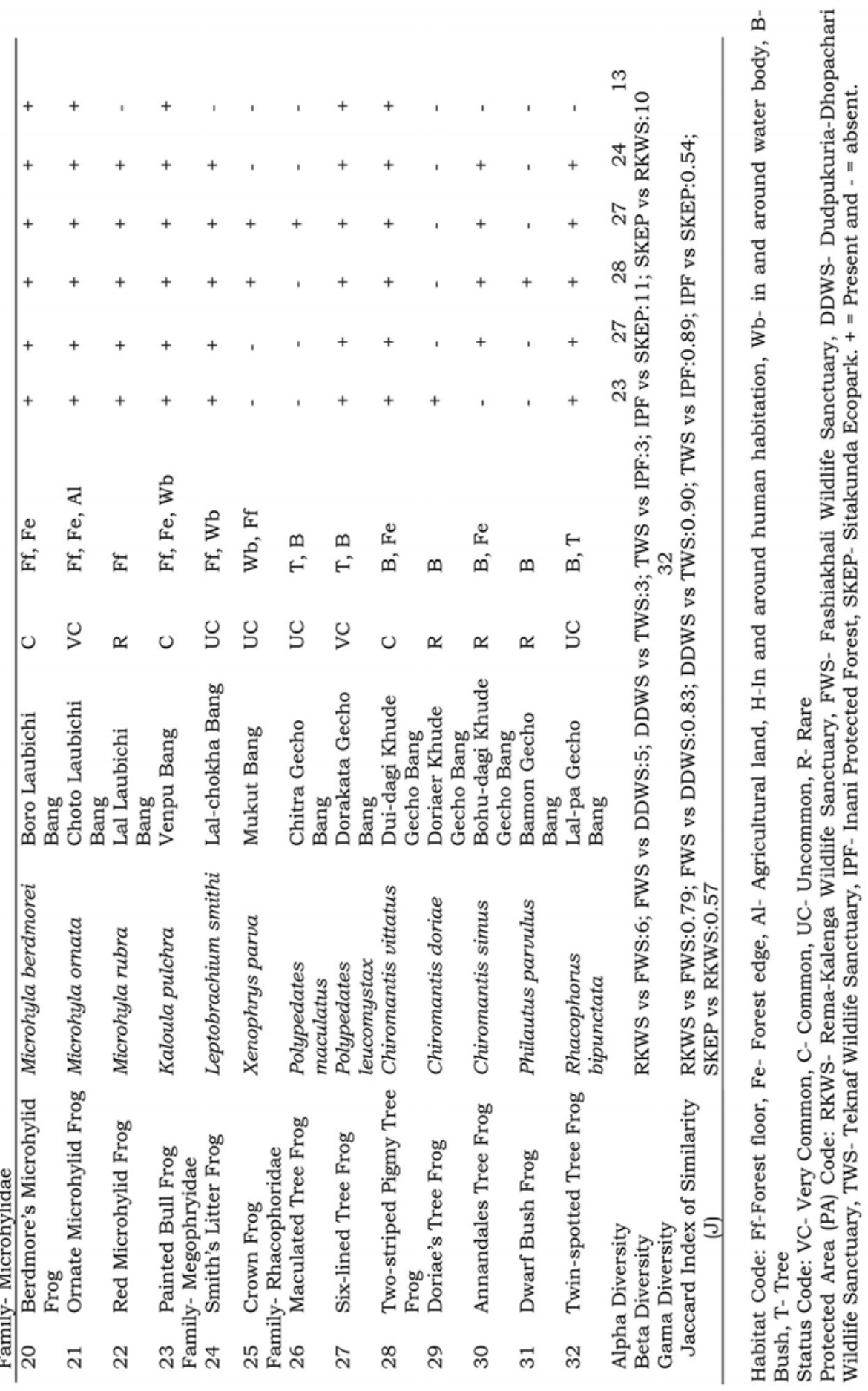


Jaccard index of similarity between the amphibian communities was very high between DDWS and TWS $(\mathrm{J}=0.90)$ followed by TWS and IPF $(\mathrm{J}=0.89)$, FWS and DDWS $(J=0.83)$, RKWS and FWS $(J=0.79)$, SKEP and RKWS $(J=0.57)$, IPF and SKEP ( $\mathrm{J}=0.54)$ (Table 1$)$.

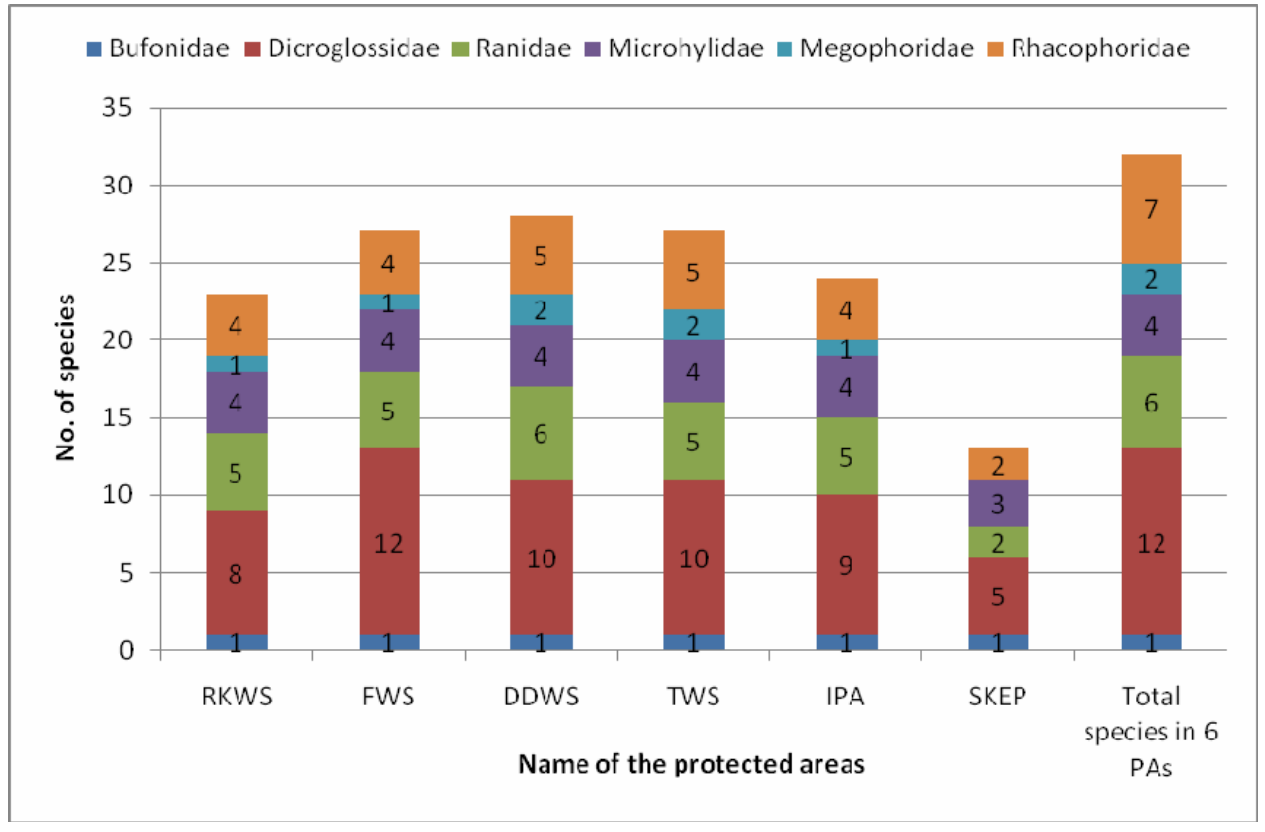

Fig. 1 Number of species in different amphibian families in six protected areas.

Status: among the 32 species recorded from six protected areas 34\% (11 species) was uncommon, 31\% (10 species) common, 19\% (6 species) rare and $16 \%$ (5 species) very common. DDWS supported the highest number of rare species (5) where as SKEP had no rare species (Fig. 2). FWS and TWS supported 9 uncommon species each followed by DDWS (8 species), IPF (6 species), RKWS (5 species) and SKEP (1 species). All the five protected areas supported 10 common species each except SKEP (7 species). Five very common species were recorded from all the protected areas (Fig. 2).

Habitat preference: Fifty percent amplibian species used more than two habitats, $34 \%$ species (11 species) used two habitats where as only $16 \%$ (5 species) restricted to a single habitat. Species those are restricted to a single habitat were rare where as species those use two or more habitats were common (Fig. 3). Most of the species (20 species) were found to use forest edge habitats followed by water body (19 species), forest floor (15 species), Agricultural land (13 species), bushes (7 species) and tree (3 species). 


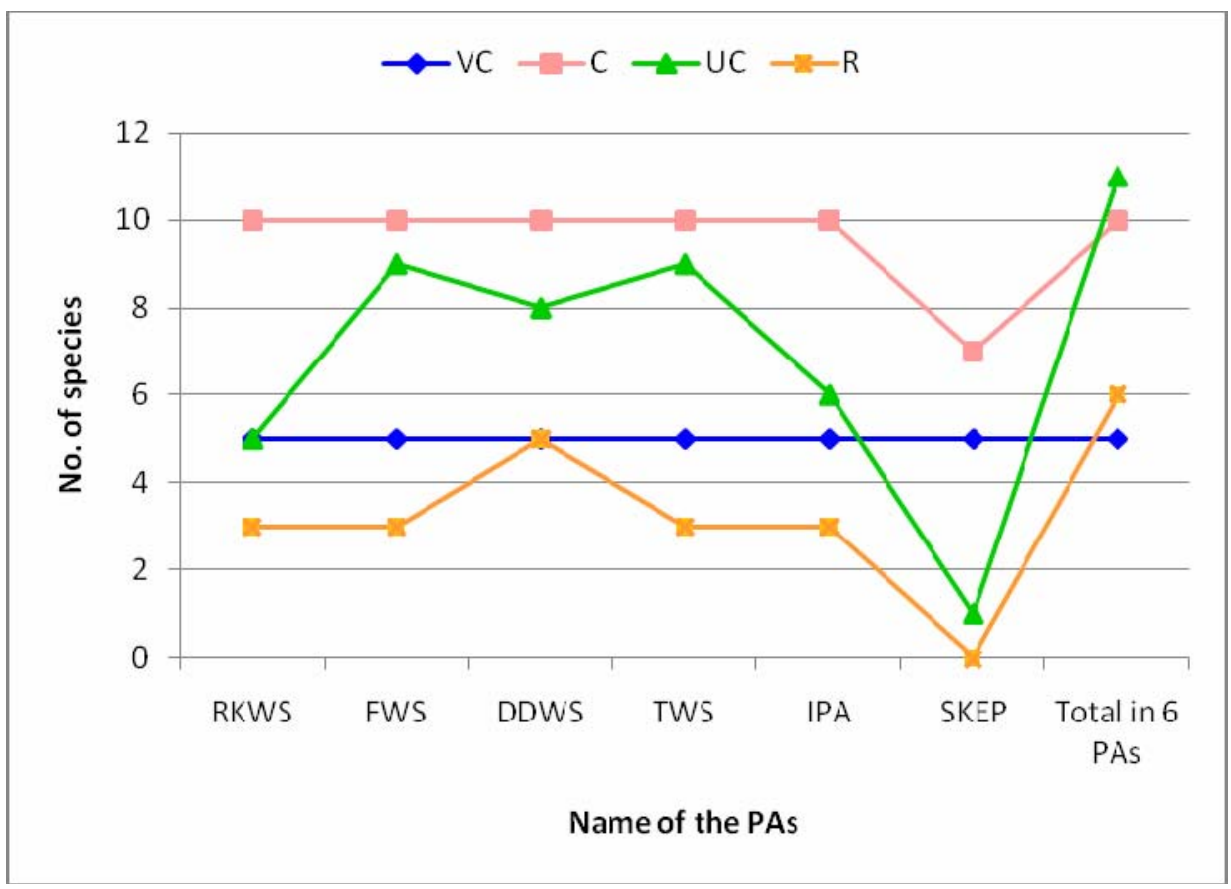

Fig.2 Status of amphibian species in different protected areas.

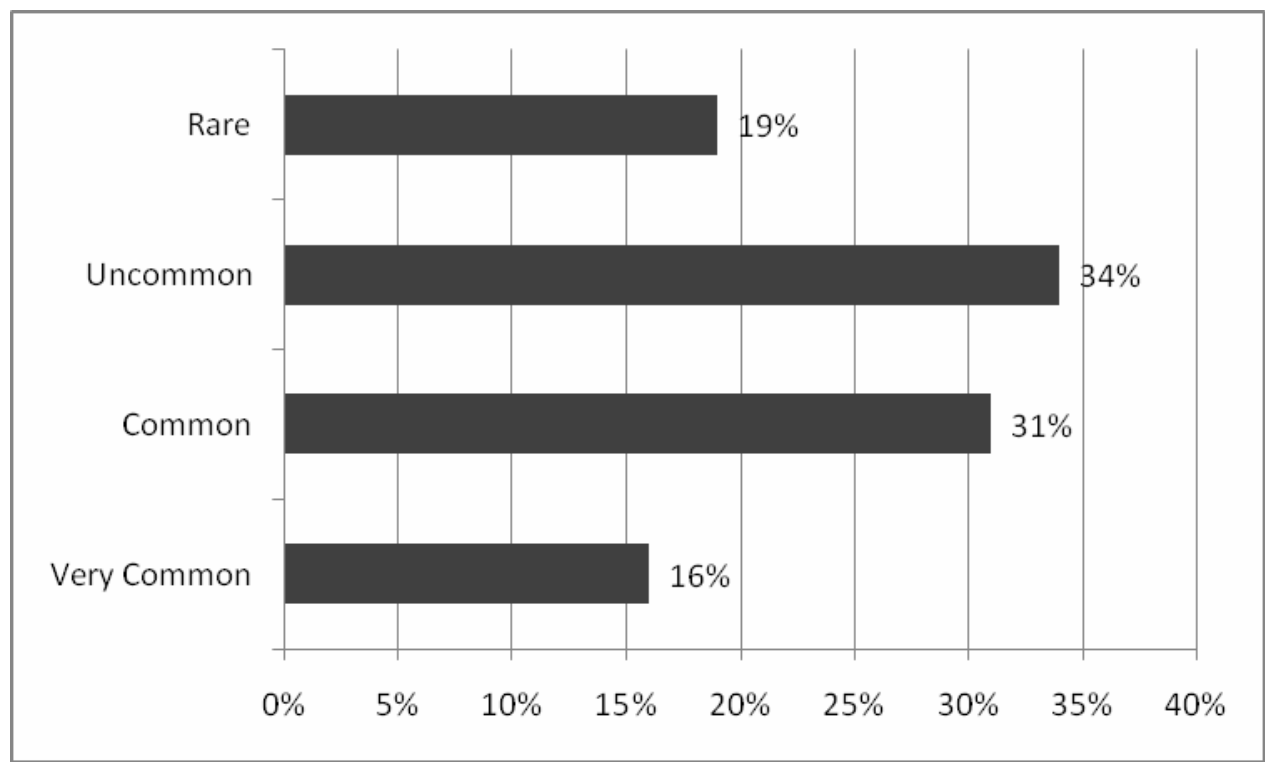

Fig. 3 Status of amphibian species in relation to habitat use. 
Though protected areas cover only $10 \%$ forest areas of Bangladesh but are the harbor of many threatened wild species as well as amphibians. Thirty two amphibian species were recorded from six PAs which is about $76 \%$ of the total amphibian population of the country. Habitats of DDWS are diverse and also the part of the Chittagong Hill Tracts, these could be the reasons for having the highest alpha diversity (28). Fashiakhali Wildlife Sanctuary also have natural forest patches, open areas, planted forest and freshwater marshy areas. These diverse habitats support a high alpha diversity (27) of amphibians. Teknaf Wildlife Sanctuary also has diverse habitats; its hilly areas, natural and planted forest patches, permanent water creeks and bushy habitats support the same alpha diversity (27) as FWS. IPF also has diverse habitats including natural forest patches and has higher alpha diversity (24) than RKWS (23).

Two frog species, green frog (Euphlyctis hexadactylus) and coastal bull frog (Hoplobatrachus litoralis) were only recorded from Fashiakhali Wildlife Sanctuary. FWS has some permanent freshwater marshes with aquatic vegetations; those provide perfect habitats for green frog. Green frog is one of the rare frog species of Bangladesh but fairly common beside the outer fringe of Sundarbans, Savar and northeastern parts of the country. This report from FWS confirms its distribution in southeast of Bangladesh. Torrent frog (Amolops marmoratus) and Dwarf bush frog (Philautus parvulus) were recorded only from DDWS. The rocky creeks in natural forest patch support Torrent frog in DDWS. Maculated tree frog (Polypedates maculatus) was only recorded from TWS and Doriae's tree frog (Chiromantis doriae) was only recorded from RKWS among the six PAs.

Beta diversity were lower (3) in DDWS vs TWS and TWS vs IPF each whereas Jaccard index $(\mathrm{J})$ of similarity among the amphibian community were higher $(\mathrm{J}=$ 0.90 and 0.89 respectively). These indicate that very similar species of amphibians were found in the habitats of these four PAs. On the other hand, beta diversity were higher in IPF vs SKEP (11) and SKEP vs RKWS (10) and values of Jaccard index were lower ( $\mathrm{J}=0.54$ and 0.57 respectively). These indicate that amphibian communities in these protected areas were quite different. SKEP has very few natural forest patches and most of the areas are planted. It does not have as diverse habitats as other PAs and is more disturbed by the visitors. Moreover, as an Eco-park it has not as strong legal protection as other PAs.

Forest edges enjoy the environments of an ecotone, thus the highest number of amphibian species were recorded from there. A good number of species use forest floor habitats. Painted bull frog (Kalaula pulchra) and Smith's litter frog (Leptobrachium smithi) are two fossorial species and use leaf litter of the forest. 
Leaf litter habitats also provide good hibernating places during winter. Twinspotted tree frog (Rhacophorus bipunctata) was recorded only from the natural forest patches of five PAs except SKEP. No natural habitat existed for Twinspotted tree frog in Sitakunda Eco-park. Red microhylid (Microhyla rubra) is another rare species of Bangladesh and only recorded from the natural forest patches thus absent in SKEP. Species using two or more habitats were common than the species restricted to a single habitat and probably less vulnerable to changes in environmental gradients.

Amphibians of protected areas are facing different degree of threats due to various anthropogenic effects (Hasan and Akhtar, 2013). Amphibian's habitats of these PAs are squeezing day by day. Illegal felling is one of the major reasons for habitat destruction for amphibians in these PAs. Forest coverage is reducing and ultimately forests are losing water and moisture conservation abilities. Landslides and soil erosion are covering forest creeks thus water sources are reducing in forests which eventually hampering breeding of many amphibian species. Intentional forest fire during winter is a serious problem for some PAs especially in RKWS. Forest fires destroy leaf litter (hibernation shelter) and kill many species of amphibians. In some places especially in DDWS, FWS and TWS local people consume frog legs. Mass consumption of frog legs is a serious threat for large species of frogs like Hoplobatrachus tigerinus and Hoplobatrachus litoralis though frog leg consumption is illegal. Awareness building among the local people of these PAs and proper implementation of existing laws can play effective roles for the conservation of amphibians.

Natural forest patches are more important for supporting rare amphibian species than planted forests. The natural forest of DDWS supported highest number of amphibians as well as rare species. Thus, amphibians are facing continuous threat of extinction due to habitat destroction and consumption for food, awareness building and implementation of law among the people living in and around the PAs coold play an important role for the conservation of amphibians in Bangladesh.

Acknowledgements: The study was conducted as a part of the biodiversity monitoring in selected protected areas of Bangladesh (BioTrack) project, funded by Arannyak Foundation, Bangladesh and implemented by the wildlife research group of the Department of Zoology, Jahangirnagar University, we are thankful to them. We are thankful to the Forest Department of Bangladesh for providing permission and support during the field works. We are also grateful to the authority of Wildlife Rescue Center (WRC) of Jahangirnagar University for their logistic support and the bioTrack Team members for their painstaking field work. 


\section{LITERATURE CITED}

AHMED, M. F., DAS, A., and DUTTA, S. K. 2009. Amphibians and Reptiles of Northeast India: A Photographic Guide. Aaranyak, Assam, India.163 pp.

BOSSUYT, F. and DUBOIS, A. 2001. A review of the frog genus Philautus Gistel, 1848 (Amphibia, Anura, Ranidae, Rhacophorinae). Zeylanica. 6(1):1-122.

DAS, A. 2008. Diversity and distribution of herpetofauna and evaluation of conservation status in BARAIL HERPETOFAUNA PROJECT, Final Report- March 2011. Conservation status in Barail Hill Range (including Barail Wildlife Sanctuary), Assam, Northeast India. Aaranyak. Guwahati. $94 \mathrm{pp}$.

DUBOIS, A. 1975. Un nouveau complexe d'especes jumelles distinguees par le chant: les grenouilles du Nepal voisines de Rana limnocharis Boei (Amphibiens, Anoures). Comptes Rendus Academy of Science Paris (D). 281:1717-1720.

DUTTA, S. K. and MANAMENDRA-ARACHCHI, K. 1996. The Amphibian Fauna of Sri Lanka. Wildlife Heritage Trust of Sri Lanka, Colombo. 232 pp.

FAO 2001. Global Ecological Zoning for the Global Forest Resources Assessment 2000. FRA. Working Paper 56. FAO Rome.

FEEROZ, M.M. (ed.), 2013. Biodiversity of Protected Areas of Bangladesh, Vol. III: Teknaf Wildlife Sanctuary. Arannayk Foundation, Dhaka. pp 113-120.

FEEROZ, M.M., HASAN, M.K. and HOSSAIN, M.K. 2012. Biodiversity of Protected Areas of Bangladesh, Vol. II: Dudpukuria-Dhopachari Wildlife Sanctuary. Arannayk Foundation, Dhaka.

FEEROZ, M. M., HASAN, M.K. and KHAN, M.M.H. 2011. Biodiversity of Protected areas of Bangladesh, Vol. I: Rema-Kalenga Wildlife Sanctuary. Arannayk Foundation, Dhaka. pp 216.

FROST , D. R. 2013. Amphibian Species of the World: An Online Reference. Version 5.6 (9 January 2013). Electronic Database accessible at http://research.amnh.org/herpetology/ amphibia/index.html. American Museum of Natural History, New York, USA.

HALL, R. J., and HENRY, P. F. P. 1992. Assessing effects of pesticides on amphibians and reptiles: Status and needs. Herpetol. J. 2(3): 65-71.

HASAN, M.K. and AKHTAR, S. 2013. Amphibians of Teknaf Wildlife Sanctuary. In: (Ed., FEEROZ, M.M.) . Biodiversity of Protected Areas of Bangladesh, Vol. III: Teknaf Wildlife Sanctuary. Arannayk Foundation, Dhaka. pp 113-120.

IUCN. 2000. Red Book of Threatened Amphibians and Reptiles of Bangladesh. IUCN- The World Conservation Union, Dhaka. $95 \mathrm{pp}$.

JACCARD, P. 1901. Étude comparative de la distribution florale dans une portion des Alpes et des Jura. Bulletin de la Société Vaudoise des Sciences Naturelles. 37: 547-579.

KABIR, S.M.H., AHMED, M., AHMED, A.T.A., AHMED, Z.U., BEGUM, Z.N.T., HASSAN, M.A. and KHONDOKER, M. (eds.). 2009. Encyclopedia of Flora and Fauna of Bangladesh, Vol. 25: Amphibians and Reptiles. Asiatic Society of Bangladesh, Dhaka. 204 pp.

KHAN, M.A.R. 2004. Checklist of the herpetofauna of Bangladesh. Cobra. 57: 1-31.

KHAN, DR.R. 2010. Wildlife of Bangladesh, From Amphibia to Mammalia- A Checklist. Shahitya Prakash, Dhaka. 127 pp.

KHAN, M.M.H. 2008. Protected Areas of Bangladesh- A Guide to Wildlife. Nishorgo Program, Bangladesh Forest Department, Dhaka, Bangladesh. 304 pp.

NFA, 2007. National Forest and Tree Resources Assessment 2005-2007, Bangladesh. Ministry of Environment and Forest (MoEF), Bangladesh.

NISHAT, A., HUQ, S.M.I., BARUA, S.P., REZA, A.H.M.A., KHAN, A.R. and MONIRUZZAMAN, A.S. (eds.). 2002. Bio-ecological Zones of Bangladesh. IUCN Bangladesh Country Office, Bangladesh, Dhaka. xii+141 pp. 
SMITH, M. A. 1935. The fauna of British India, including Ceylon and Burma. Reptilia and Amphibia. Vol. II.- Sauria. Taylor and Francis, London. xiii +440 pp.

SMITH, M.A. 1943. The Fauna of British India, Ceylon and Burma, including the whole of the Indochinese subregion. Reptilia and Amphibia. Vol. III.- Serpents. Taylor and Francis, London. xii+583.

STANFORD, C.B. 1991. The capped langur in Bangladesh: Behavioural Ecology and Reproductive Tactics. Vol. 26. Karger Publishers. 163 pp.

(Manuscript received on 22 June 2013; revised on 22 May 2014) 